OPEN ACCESS

Edited by:

Roman Sobotka

Czech Academy of Sciences,

Czech Republic

Reviewed by:

Anja Liszkay,

Centre National de la Recherche

Scientifique, France

Esa Tyystjärvi,

University of Turku, Finland

${ }^{*}$ Correspondence:

Imre Vass

vass.imre@brc.mta.hu

Specialty section:

This article was submitted to

Plant Cell Biology,

a section of the journal

Frontiers in Plant Science

Received: 04 January 2016

Accepted: 24 March 2016

Published: 08 April 2016

Citation:

Rehman AU, Kodru S and Vass I (2016) Chloramphenicol Mediates Superoxide Production in Photosystem II and Enhances Its

Photodamage in Isolated Membrane

Particles. Front. Plant Sci. 7:479.

doi: 10.3389/fpls.2016.00479

\section{Chloramphenicol Mediates Superoxide Production in Photosystem II and Enhances Its Photodamage in Isolated Membrane Particles}

\author{
Ateeq Ur Rehman, Sandeesha Kodru and Imre Vass* \\ Institute of Plant Biology, Biological Research Centre of the Hungarian Academy of Sciences, Szeged, Hungary
}

Chloramphenicol (CAP) is an inhibitor of protein synthesis, which is frequently used to decouple photodamage and protein synthesis dependent repair of Photosystem II during the process of photoinhibition. It has been reported earlier that CAP is able to mediate superoxide production by transferring electrons from the acceptor side of Photosystem I to oxygen. Here we investigated the interaction of CAP with Photosystem II electron transport processes by oxygen uptake and variable chlorophyll fluorescence measurements. Our data show that CAP can accept electrons at the acceptor side of Photosystem II, most likely from Pheophytin, and deliver them to molecular oxygen leading to superoxide production. In addition, the presence of CAP enhances photodamage of Photosystem II electron transport in isolated membrane particles, which effect is reversible by superoxide dismutase. It is concluded that CAP acts as electron acceptor in Photosystem II and mediates its superoxide dependent photodamage. This effect has potential implications for the application of CAP in photoinhibitory studies in intact systems.

Keywords: photoinhibition, Photosystem II, chloramphenicol, superoxide

\section{INTRODUCTION}

Photosynthesis is a process in which green plants, algae and cyanobacteria utilize energy from sunlight to manufacture carbohydrates from carbon dioxide and water. This process is the ultimate source of energy for all plants to drive their metabolic processes. Too much light reaching the photosynthetic apparatus can cause photodamage and ultimately can lead to the death of a cell. This stress situation is known as photoinhibition (Arntzen et al., 1984; Aro et al., 1993; Vass and Aro, 2008). The major damage of the photosynthetic apparatus under high light conditions is impairment of electron transport in the Photosystem II (PSII) complex, as well as damage of the D1 reaction center subunit (Ohad et al., 1984; Prasil et al., 1992). Important mediators of photodamage in plant cells are the various reactive oxygen species (ROS), such as singlet excited oxygen, free radicals (superoxide and hydroxyl ions) and peroxides, which are produced mainly in the chloroplasts and mitochondria (Apel and Hirt, 2004). The activity of the photodamaged PSII complex can be restored via the so called PSII repair cycle in which de novo synthesis of the damaged D1 subunits plays a key role (Aro et al., 1993; Baena-Gonzalez and Aro, 2002; Komenda et al., 2007; Nixon et al., 2010). 
Light stress to PSII becomes a problem for photosynthetic capacity when the rate of photodamage exceeds the capacity of repair processes. Therefore, it is important to monitor separately the rates of photodamage and of the protein synthesis dependent repair. Decoupling of photodamage and repair can be achieved by protein synthesis inhibitors, such as lincomycin or chloramphenicol (CAP), which inhibit translation elongation in chloroplasts (Mulo et al., 2003; Chow et al., 2005; Tikkanen et al., 2014) or in cyanobacterial cells (Constant et al., 1997; Nishiyama et al., 2001, 2005; Sicora et al., 2003; Takahashi and Murata, 2005; Takahashi et al., 2009). While there are no reports concerning the participation of lincomycin in photosynthetic electron transport, CAP has been reported to accept electrons from the acceptor side of Photosystem I and to transfer them to molecular oxygen leading to superoxide production (Okada et al., 1991). Superoxide radicals have high reactivity, therefore, it is expected that locally generated superoxide will induce damaging effects in the vicinity of its production. This finding has been considered as a source of potential artifact by several research groups, who used lincomycin instead of CAP in photoinhibition studies (Tyystjarvi and Aro, 1996; Constant et al., 1997; Tyystjarvi et al., 2002; Chow et al., 2005; Campbell and Tyystjärvi, 2012; Miyata et al., 2012; Tikkanen et al., 2014). However, other groups kept using CAP in measurements of PSII photodamage (Nishiyama et al., 2001, 2005; Takahashi and Murata, 2005; Takahashi et al., 2009).

In the present work we investigated whether CAP has the capacity to interact directly with PSII electron transport in isolated membrane particles. Our data show that CAP acts as an electron acceptor to PSII and mediates superoxide production, which enhances photodamage of PSII.

\section{MATERIALS AND METHODS}

\section{PSII Membrane Preparation}

Photosystem II membrane particles were isolated from fresh spinach leaves as described earlier (Vass et al., 1987) and suspended in buffers containing $40 \mathrm{mM}$ MES-NaOH (pH 6.5), $15 \mathrm{mM} \mathrm{MgCl}_{2}, 15 \mathrm{mM} \mathrm{CaCl}_{2}$ and $1 \mathrm{M}$ betaine, respectively. PSII membranes were stored in $-80^{\circ} \mathrm{C}$ for further use.

\section{Light Induced Oxygen Uptake Measurements}

$\mathrm{O}_{2}$ uptake rates in PSII particles were measured by using a Hansatech DW2 $\mathrm{O}_{2}$ electrode at $4^{\circ} \mathrm{C}$ under illumination with $500 \mu$ mole $\mathrm{m}^{-2} \mathrm{~s}^{-1}$ light intensity. The total duration of illumination was $1 \mathrm{~min}$. DCMU, which blocks electron transport at the $\mathrm{Q}_{\mathrm{B}}$ site of PSII was also added at a concentration of $10 \mu \mathrm{M}$ when indicated. In order to confirm superoxide formation the rate of oxygen uptake was also measured in the presence of 20 units/mg superoxide dismutase (SOD) that converts $\mathrm{O}_{2}^{-}$partly back to $\mathrm{O}_{2}$, as well as after addition of 1000 units of bovine serum catalase that converts $\mathrm{H}_{2} \mathrm{O}_{2}$, which is produced by SOD from $\mathrm{O}_{2}^{-}$, to $\mathrm{H}_{2} \mathrm{O}$ and $\mathrm{O}_{2}$. One mililiter aliquot of PSII membrane

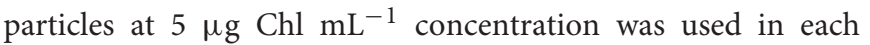
measurement.

\section{Photoinhibitory Treatment}

The PSII particles were resuspended at $5 \mu \mathrm{g} \mathrm{Chl} \mathrm{mL} \mathrm{m}^{-1}$ in $40 \mathrm{~mL}$ volume and illuminated with $500 \mu$ mole $\mathrm{m}^{-2} \mathrm{~s}^{-1}$ light intensity in the presence and absence of CAP $(200 \mu \mathrm{g} / \mathrm{mL})$. The temperature during illumination was maintained at $4^{\circ} \mathrm{C}$. The samples were also illuminated in the presence of SOD (20 units $\mathrm{mg}^{-1}$ ). For monitoring PSII activity the rate of $\mathrm{O}_{2}$ evolution was measured at the indicated time points. Photosynthetic activity of irradiated PSII membranes was also assessed by measuring the so called OJIP transient of variable Chl fluorescence during application of a 2 s saturating pulse (Strasser et al., 1995) by using an FL-3000 fluorometer (PSI). $\mathrm{F}_{\mathrm{v}} / \mathrm{F}_{\mathrm{m}}$ was obtained by calculating $\left(\mathrm{F}_{\mathrm{m}}-\mathrm{F}_{\mathrm{o}}\right) / \mathrm{F}_{\mathrm{m}}$, where $\mathrm{F}_{\mathrm{o}}$ and $\mathrm{F}_{\mathrm{m}}$ represent the minimum fluorescence in dark adapted sample, and the maximal fluorescence yield under continuous saturating light, respectively.

\section{RESULTS AND DISCUSSION}

\section{CAP Acts as Electron Acceptor in PSII}

Chloramphenicol has been reported earlier to take up electrons at the acceptor side of PSI (Okada et al., 1991). In order to check if similar phenomenon occurs in PSII, or not, the so

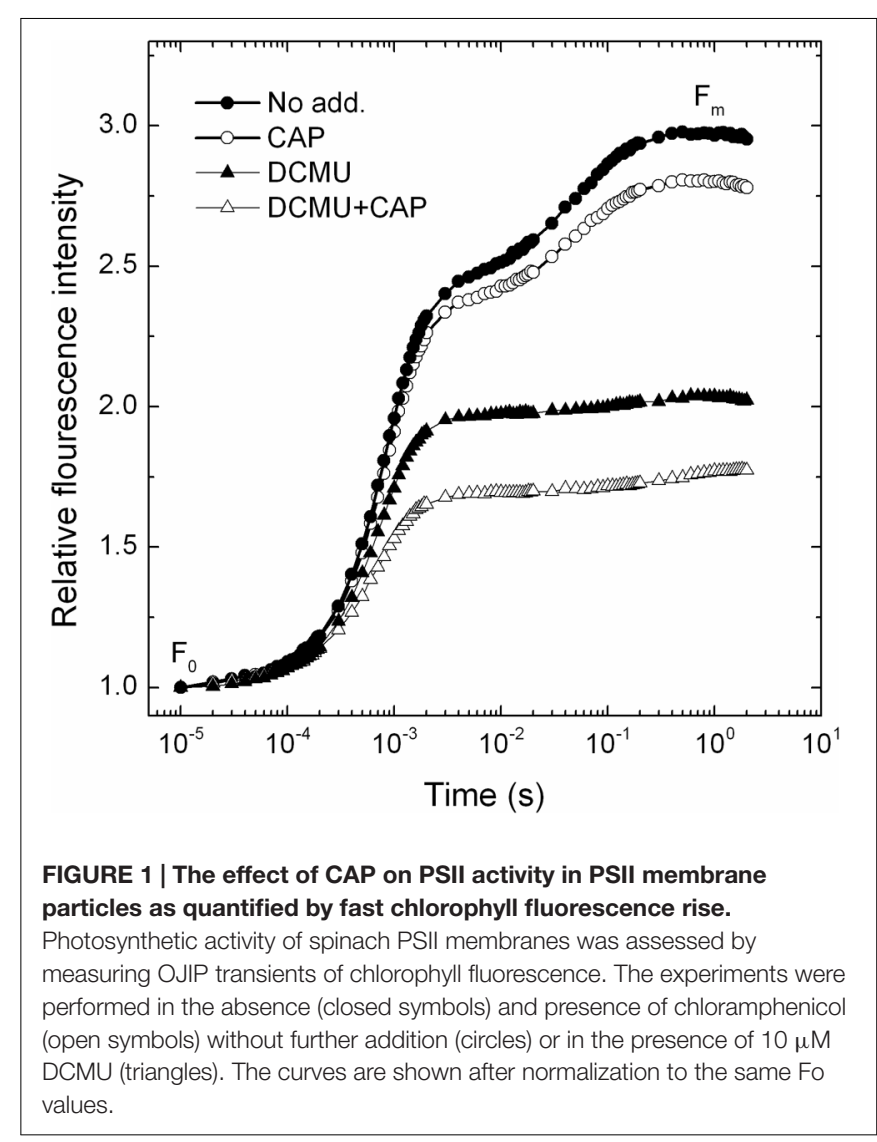


called OJIP Chl fluorescence transient was measured in the absence and presence of CAP. As shown in Figure 1 the maximal fluorescence level $\left(\mathrm{F}_{\mathrm{m}}\right)$ was decreased in the presence of CAP (open circles), which is consistent with the presence of an electron acceptor that prevents complete reduction of the $Q_{A}$ primary quinone electron acceptor. In order to verify if CAP takes up electrons before or after the $\mathrm{Q}_{\mathrm{B}}$ binding site we used DCMU, which inhibits electron transport from $\mathrm{Q}_{\mathrm{A}}^{-}$to $\mathrm{Q}_{\mathrm{B}}$ by preventing $\mathrm{PQ}$ binding to the $\mathrm{Q}_{\mathrm{B}}$ site. Interestingly CAP induced decrease of the $F_{m}$ level also in the presence of DCMU (Figure 1, open triangles), which indicates that CAP takes up electrons from PSII before the DCMU block, i.e., either directly from $\mathrm{Q}_{\mathrm{A}}^{-}$or from $\mathrm{Phe}^{-}$. Considering the very negative redox potential of $\mathrm{CAP}, \mathrm{E}_{\mathrm{m}}\left(\mathrm{CAP} / \mathrm{CAP}^{-}\right)=-543 \mathrm{mV}$ (Kapoor and Varshney, 1997), the efficiency of electron transfer from $Q_{A}^{-}$ $\left(\mathrm{E}_{\mathrm{m}}\left(\mathrm{Q}_{\mathrm{A}} / \mathrm{Q}_{\mathrm{A}}^{-}\right)=-120\right.$ to $-140 \mathrm{mV}$, Shibamoto et al., 2009) to CAP should be very low. On the other hand the redox potential of Phe $\left[\mathrm{E}_{\mathrm{m}}\left(\mathrm{Phe} / \mathrm{Pheo}^{-}\right)=-505\right.$ to $-535 \mathrm{mV}$ (Shibamoto et al., 2009; Allakhverdiev et al., 2010)] allows energetically efficient interaction with $\mathrm{Phe}^{-}$. Therefore, although the lifetime of $\mathrm{Phe}^{-}$ is very short (ca. 200 ps) it is a possible candidate to act as an electron donor for the reduction of CAP. This finding is in agreement with previous suggestions that $\mathrm{Phe}^{-}$can act as direct electron donor to $\mathrm{O}_{2}$ and can support superoxide production (Pospísil, 2012).

\section{CAP Induces Superoxide Production in Isolated PSII Particles}

It has been reported previously (Okada et al., 1991) that CAP mediates superoxide production in thylakoids by transferring electrons from the PSI acceptor side to oxygen. Since we have shown that CAP functions not only as PSI electron acceptor, but takes up electrons also from PSII it has a potential to produce superoxide in PSII complexes as, well.

In contrast to molecular oxygen superoxide does not produce amperometric signal in Clark-type oxygen electrodes. Therefore, conversion of $\mathrm{O}_{2}$ to $\mathrm{O}_{2}^{-}$leads to oxygen consumption, which can be easily followed by oxygen uptake measurements. In order to investigate CAP mediated superoxide production we measured $\mathrm{O}_{2}$ uptake under various conditions. The data in Figure 2A show that CAP enhances light induced $\mathrm{O}_{2}$ uptake in PSII particles. This effect is partly reversible by $\mathrm{SOD}$, which converts $1 \mathrm{O}_{2}^{-}$ molecule to $1 / 2 \mathrm{O}_{2}$ and $1 / 2 \mathrm{H}_{2} \mathrm{O}_{2}$. Addition of catalase together with $\mathrm{SOD}$ almost completely eliminated the $\mathrm{O}_{2}$ uptake, which is consistent with the conversion of $1 / 2 \mathrm{H}_{2} \mathrm{O}_{2}$ to $1 / 2 \mathrm{H}_{2} \mathrm{O}+1 / 2 \mathrm{O}_{2}$. These data demonstrate that CAP can indeed mediate superoxide production in PSII. DCMU had only a minor inhibitory effect on the $\mathrm{O}_{2}$ uptake, which is consistent with the idea that CAP transfers electrons to oxygen from a PSII acceptor located before the $\mathrm{Q}_{\mathrm{B}}$ site.

\section{CAP Enhances Photodamage of PSII in Isolated Membrane Particles}

In order to check if CAP mediated superoxide production has any influence on the rate of photodamage PSII membrane particles were exposed to high light treatment in the absence and presence

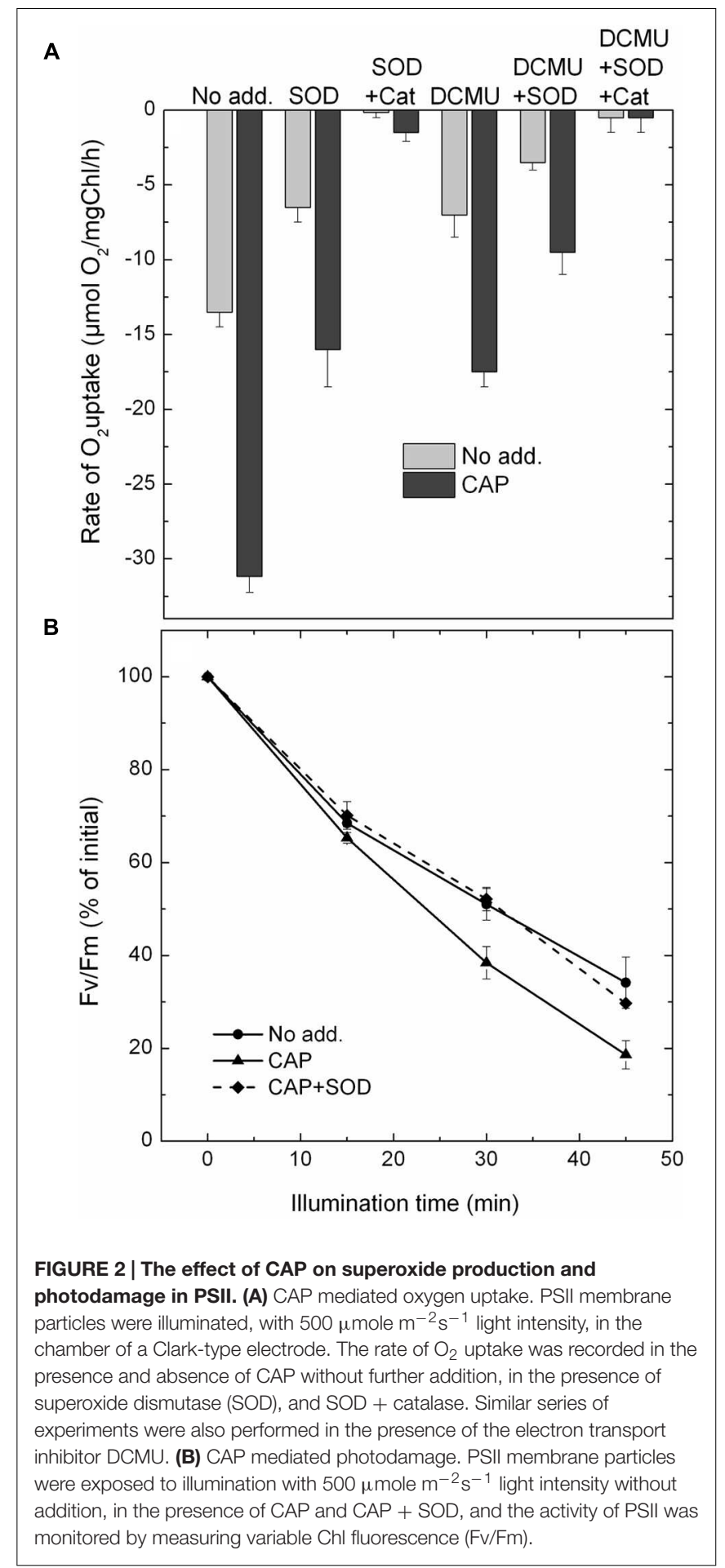

of CAP. According to the data shown in Figure 2B, light induced loss of PSII activity, as assessed by variable Chl fluorescence measurements, occurred faster in the presence than in the absence of CAP. Interestingly, the CAP induced enhancement of PSII photodamage was almost completely reversed when SOD was added together with CAP during the photoinhibitory treatment (Figure 2B). These data demonstrate that CAP induces 
enhanced PSII photodamage via production of superoxide in BBY particles.

\section{CONCLUSION}

Our data show that CAP accepts electrons from the PSII complex at a site located before the $\mathrm{Q}_{\mathrm{B}}$ quinone electron acceptor, most likely from $\mathrm{Phe}^{-}$. This process leads to superoxide production, which induces enhanced photodamage of PSII in isolated membrane particles. This side effect of CAP has potentially important implications regarding its application as protein synthesis inhibitor in photoinhibitory studies. Besides blocking the repair cycle of PSII CAP may accelerate the rate of photodamage also in intact systems leading to artifacts concerning the mechanism of photoinhibition. The in vivo effects of CAP are currently

\section{REFERENCES}

Allakhverdiev, S. I., Tomo, T., Shimada, Y., Kindo, H., Nagao, R., and Klimov, V. V. (2010). Redox potential of pheophytin a in photosystem II of two cyanobacteria having the different special pair chlorophylls. Proc. Natl. Acad. Sci. U.S.A. 107, 3924-3929. doi: 10.1073/pnas.0913460107

Apel, K., and Hirt, H. (2004). Reactive oxygen species: metabolism, oxidative stress, and signal transduction. Annu. Rev. Plant Biol. 55, 373-399. doi: 10.1146/annurev.arplant.55.031903.141701

Arntzen, C. J., Kyle, D. J., Wettern, M., and Ohad, I. (1984). Photoinhibition: a consequence of the accelerated breakdown of the apoprotein of the secondary electron acceptor of Photosystem II. Biosynth. Photosynth. Apparatus 82, 313-324.

Aro, E.-M., Virgin, I., and Andersson, B. (1993). Photoinhibition of Photosystem II. Inactivation, protein damage and turnover. Biochim. Biophys. Acta 1143, 113-134. doi: 10.1016/0005-2728(93)90134-2

Baena-Gonzalez, E., and Aro, E.-M. (2002). Biogenesis, assembly and turnover of Photosystem II units. Philos. Trans. R. Soc. Lond. B Biol. Sci. 357, 1451-1460. doi: $10.1098 /$ rstb.2002.1141

Campbell, D. A., and Tyystjärvi, E. (2012). Parameterization of photosystem II photoinactivation and repair. Biochim. Biophys. Acta 4660, 258-265. doi: 10.1016/j.bbabio.2011.04.010

Chow, W. S., Lee, H.-Y., He, J., Hendrickson, L., Hong, Y. -N., and Matsubara, S. (2005). Photoinactivation of Photosystem II in leaves. Photosynth. Res. 84, 35-41. doi: 10.1007/s11120-005-0410-1

Constant, S., Perewoska, I., Alfonso, M., and Kirilovsky, D. (1997). Expression of the psbA gene during photoinhibition and recovery in synechocystis PCC 6714: inhibition and adamage of transcritptional and translational machinery prevent the restoration of Photosystem II activity. Plant Mol. Biol. 34, 1-13. doi: 10.1023/A:10057548 23218

Kapoor, S., and Varshney, L. (1997). Redox reactions of chloramphenicol and some aryl peroxyl radicals in aqueous solutions:? A pulse radiolytic study. J. Phys. Chem. A 101, 7778-7782. doi: 10.1021/jp971055z

Komenda, J., Tichy, M., Prasil, O., Knoppová, J., Kuviková, S., de Vries, R., et al. (2007). The exposed N-terminal tail of the D1 subunit is required for rapid D1 degradation during Photosystem II repair in Synechocystis sp PCC 6803. Plant Cell 19, 2839-2854. doi: 10.1105/tpc.107.053868

Miyata, K., Noguchi, K., and Terashima, I. (2012). Cost and benefit of the repair of photodamaged photosystem II in spinach leaves: roles of acclimation to growth light. Photosynth. Res. 113, 165-180. doi: 10.1007/s11120-0129767-0

Mulo, P., Pursiheimo, S., Hou, C. X., Tyystjarvi, T., and Aro, E.-M. (2003). Multiple effects of antibiotics on chloroplast and nuclear gene expression. Funct. Plant Biol. 30, 1097-1103. doi: 10.1071/FP03149 under investigation and will be presented in a forthcoming publication.

\section{AUTHOR CONTRIBUTIONS}

IV proposed the research topic, designed part of the experiments and contributed to writing of the manuscript. AUR, designed part of the experiments and contributed to data analysis and writing of the manuscript. SK performed most of the experiments and prepared the figures.

\section{ACKNOWLEDGMENT}

This work was supported from a grant by the Hungarian granting agency OTKA (NN-110960).

Nishiyama, Y., Allakhverdiev, S. I., and Murata, N. (2005). Inhibition of the repair of Photosystem II by oxidative stress in cyanobacteria. Photosynth. Res. 84, 1-7. doi: 10.1007/s11120-004-6434-0

Nishiyama, Y., Yamamoto, H., Allakhverdiev, S. I., Inaba, H., Yokota, A., and Murata, N. (2001). Oxidative stress inhibits the repair of photodamage to the photosynthetic machinery. EMBO J. 20, 5587-5594. doi: 10.1093/emboj/20.20.5587

Nixon, P. J., Michoux, F., Yu, J., Boehm, M., and Komenda, J. (2010). Recent advances in understanding the assembly and repair of photosystem II. Ann. Bot. 106, 1-16. doi: 10.1093/aob/mcq059

Ohad, I., Kyle, D. J., and Arntzen, C. J. (1984). Membrane protein damage and repair: removal and replacement of inactivated 32-kilodalton polypeptides in chloroplast membranes. J. Cell Biol. 99, 481-485. doi: 10.1083/jcb.99.2.481

Okada, K., Satoh, K., and Katoh, S. (1991). Chloramphenicol is an inhibitor of photosynthesis. FEBS Lett. 295, 155-158. doi: 10.1016/0014-5793(91)81407-Y

Pospísil, P. (2012). Molecular mechanisms of production and scavenging of reactive oxygen species by photosystem II. Biochim. Biophys. Acta 1817, 218231. doi: 10.1016/j.bbabio.2011.05.017

Prasil, O., Zer, H., Godde, D., and Ohad, I. (1992). Role of the PSII acceptor site in the lihgt induced degradation of D1. Res. Photosynth. 4, 501-504.

Shibamoto, T., Kato, Y., Sugiura, M., and Watanabe, T. (2009). Redox potential of the primary plastoquinone electron acceptor QA in photosystem II from Thermosynechococcus elongatus determined by spectroelectrochemistry. Biochemistry 48, 10682-10684. doi: 10.1021/bi901691j

Sicora, C., Máté, Z., and Vass, I. (2003). The interaction of visible and UV-B light during photodamage and repair of Photosystem II. Photosynth. Res. 75, 127-137. doi: 10.1023/A:1022852631339

Strasser, R. J., Srivastava, A., and Govindjee. (1995). Polyphasic chlorophyll a fluorescence transient in plants and cyanobacteria. Photochem. Photobiol. 61, 32-42. doi: 10.1111/j.1751-1097.1995.tb09240.x

Takahashi, S., and Murata, N. (2005). Interruption of the Calvin cycle inhibits the repair of Photosystem II from photodamage. Biochim. Biophys. Acta 1708, 352-361. doi: 10.1016/j.bbabio.2005.04.003

Takahashi, S., Whitney, S. M., and Badger, M. R. (2009). Different thermal sensitivity of the repair of photodamaged photosynthetic machinery in cultured Symbiodinium species. Proc. Natl. Acad. Sci. U.S.A. 106, 3237-3242. doi: 10.1073/pnas.0808363106

Tikkanen, M., Mekala, N. R., and Aro, E.-M. (2014). Photosystem II photoinhibition-repair cycle protects Photosystem I from irreversible damage. Biochim. Biophys. Acta 1837, 210-215. doi: 10.1016/j.bbabio.2013. 10.001

Tyystjarvi, E., and Aro, E. M. (1996). The rate constant of photoinhibition, measured in lincomycin-treated leaves, is directly proportional to light intensity. Proc. Natl. Acad. Sci. U.S.A. 93, 2213-2218. doi: 10.1073/pnas.93.5.2213 
Tyystjarvi, T., Tuominen, I., Herranen, M., Aro, E.-M., and Tyystjarvi, E. (2002). Action spectrum of psbA gene transcription is similar to that of photoinhibition in Synechocystis sp. PCC 6803. FEBS Lett. 516, 167-171. doi: 10.1016/S00145793(02)02537-1

Vass, I., and Aro, E.-M. (2008). "Photoinhibition of Photosystem II electron transport," in Primary Processes of Photosynthesis: Basic Principles and Apparatus, ed. G. Renger (Cambridge: Public Royal Society Chemistry), 393-411.

Vass, I., Ono, T. A., and Inoue, Y. (1987). Removal of $33 \mathrm{kDa}$ extrinsic protein sfecifically stabilizes the S2QA- charge paier in Photosystem II. FEBS Lett. 211, 215-220. doi: 10.1016/0014-5793(87)81439-4
Conflict of Interest Statement: The authors declare that the research was conducted in the absence of any commercial or financial relationships that could be construed as a potential conflict of interest.

Copyright (๑) 2016 Rehman, Kodru and Vass. This is an open-access article distributed under the terms of the Creative Commons Attribution License (CC BY). The use, distribution or reproduction in other forums is permitted, provided the original author(s) or licensor are credited and that the original publication in this journal is cited, in accordance with accepted academic practice. No use, distribution or reproduction is permitted which does not comply with these terms. 